pag

Business School

WORKING PAPER SERIES

\begin{tabular}{c|l} 
Working Paper & $\begin{array}{l}\text { Oil Shock Transmission to Stock } \\
\text { Market Returns: Wavelet Multivariate } \\
\text { Markov Switching GARCH Approach }\end{array}$ \\
& Rania Jammazi
\end{tabular}

http://www.ipag.fr/fr/accueil/la-recherche/publications-WP.html

IPAG Business School

184, Boulevard Saint-Germain

75006 Paris

France

IPAG working papers are circulated for discussion and comments only. They have not been peer-reviewed and may not be reproduced without permission of the authors. 


\title{
Oil Shock Transmission to Stock Market Returns: Wavelet-Multivariate Markov Switching GARCH Approach
}

\author{
Rania Jammazi $\mathrm{i}^{\mathrm{a}, \mathrm{b}, \mathrm{c}, *}$ \\ a IPAG Business School, France \\ ${ }^{\mathrm{b}}$ LAREQUAD Faculty of Management and Economic Sciences of Tunis, Boulevard du 7 novembre, \\ El Manaruniversity, B.P. 248, C.P. 2092, Tunis Cedex, Tunisia \\ ${ }^{\mathrm{c}}$ Faculty of Management and Economic Sciences of Sousse, Cité Erriadh
}

\begin{abstract}
In recent years our understanding of the nature of crude oil price shocks and their effects on the stock market returns has evolved noticeably. Evidence on spillover effects between several kinds of markets has widely been discussed around the globe whereas the transmission of shocks between crude oil market and stock market returns has received little attention. Extending earlier work in the literature, we use data on monthly crude oil returns and stock market returns of five developed countries (USA, UK, Japan, Germany and Canada) to investigate two issues that have been at the center of recent debates on the effect of crude oil shocks on the stock market returns. First, we analyze whether shocks and or volatility emanating from two major crude oil markets are transmitted to the equity markets. We do this by decomposing monthly real crude oil prices and analyzing the effect of the smooth part on the degree of the stock market instability. The motivation behind the use of the former method is that noises can affect the quality of the shock and thus increase erroneous results of the shock transmission to the stock market. Second, under the hypothesis of common increased volatility, we investigate whether these states happen around the identified international crises. In doing so, flexible model involving the dynamic properties of the Trivariate Markov switching GARCH model and the recent Harr A trous wavelet decomposition, is implemented to achieve prominent prediction of the mentioned issues. The proposed model is able to circumvent the path dependency problem that can affect the prediction's robustness and can provide useful information for investors and government agencies that have largely based their views on the notion that crude oil markets affect negatively stock market returns. Indeed, the results show that the A Haar Trous Wavelet decomposition method appears to be an important step toward improving accuracy of the smooth signal in detecting key real crude oil volatility features. Additionally, apart from UK and Japanese cases, the responses of the stock market to an oil shock depend on the geographic area for the main source of supply whether from the North Sea or from the North America (as we take two oil benchmarks WTI and Brent respectively).
\end{abstract}

Keywords: Trivariate BEKK-Markov Switching, wavelet decomposition, oil shocks, stock markets.

\footnotetext{
* Corresponding author: Tel.: (+216) 719421 46, E-mail address: jamrania2@yahoo.fr (R. Jammazi).
} 